\title{
Exploring Integrated Design Strategies for the Optimal Use of BIM
}

\author{
Hyoung-June Park and Ji-Hyun Lee \\ Assistant Professor, School of Architecture, University of Hawaii at Manoa \\ Associate Professor, Graduate School of Culture Technology, KAIST
}

\begin{abstract}
This paper introduces an experimental design studio that explores the optimal use of current digital technologies in order to employ Building Information Modeling at the early phase of design process. Based upon the outcomes from the aforementioned studio, the paper discusses the integrated design strategies for BIM in the design process. In this paper, BIM is proposed as a design tool that increases an overal design productivity more effectively and efficiently compared to BIM as a construction tool with encouraging a design communication among different partakers in the design process
\end{abstract}

Keywords : Building Information Modeling, Integrated Design Strategies, Design Modeling Methods

\section{INTRODUCTION}

Building Information Modeling (BIM) is a process of establishing manageable and sharable representations of physical and functional data that define buildings throughout their life cycles in digital format. BIM provides the continuous and immediate availability of project design scope, schedule, and cost evaluation. With BIM, an architect has two fundamental benefits in the cycle of building design process. BIM supports the management of critical design information in digital form. It allows the architect to perform the update and sharing of the information among various firms in building industry. Furthermore, BIM creates real-time, consistent relationships between digital design data with innovative parametric building modeling technology. It saves the significant amounts of time and money with increasing project productivity and flexibility in the process of form-making.

The increasing use of BIM is an interesting trend that is starting moment for an integrated digital design process. However, the usage of BIM in the design process of architectural firms and studio settings is not fully implemented due to 1 ) the linear model of existing design process (Kolarevic, 2003; Onuma, 2006), 2) already built-in computer applications for the process in most architectural firms and studio settings (Bernstein and Pittman, 2004), and 3) the various limitations of current BIM applications (Cheng, 2006). Especially the limitations of the current applications including 1) the inflexibility of generating the high complexity of descriptive geometry, 2) the difficulty of learning the applications, and 3) the low level of their interoperability with other existing applications become main hindrances to employ BIM at the early phase of design process where the architect can increase the impact of the cost and functional capabilities with low cost of design changes. Therefore, BIM for supporting design process has, up to now, some disadvantages that it has tendency to obstruct creativity while designing rather than to aid it. In this paper, various design strategies are explored for increasing the use of BIM with other design modeling methods in order to lead a designer to have a high degree of design freedom, which maximizes the creativity in the design process. Instead of employing BIM as a singular and almighty design modeling method, this paper takes a pluralistic stand point for combining various design modeling methods with considering the sequence of their use in the process.

\section{DESIGN MODELING METHODS IN DESIGN PRO- GRESS}

A standard building design process consists of four primary phases such as pre-design (programming phase or conceptual design process), schematic design, partial design development, and construction document. The construction document phase is followed by procurement, construction administration, and operation of a building. As a design project grows through the primary phases, various design modeling methods are employed for maximizing the efficiency and effectiveness of establishing a design communication for client, professionals from different disciplinary areas, and a designer itself.

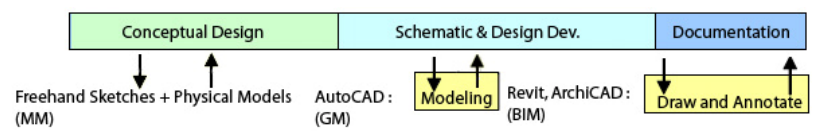

Figure 1. A diagram of a current design process

During pre-design phase in a traditional design process, Manual Modeling (MM) method for producing freehand sketches or physical models are frequently employed for developing conceptual parti or programs according to given site conditions and project requirements. Schematic design phase and partial design development phase provide an opportunity to apply various Geometric Modeling (GM) methods like SketchUp, FormZ, Rhinoceros 3D, and AutoCAD for advanced form-making explorations and design problem solving in details. Construction document phase utilizes BIM method with parametric modeling programs like CATIA, Solidworks, and Proengineer from engineering side and Autodesk Revit or ArchiCAD from architecture side in order to take advantages of the use of 
BIM. The following figure shows effect/effort (productivity) in different phases of the design process with the use of BIM. Graph 4 in the figure indicates that if we are able to use BIM at the early phase of the design process, this early adoption of BIM will produce the remarkable amount of impacts on cost \& functional capabilities in a design project and the low cost of design changes.

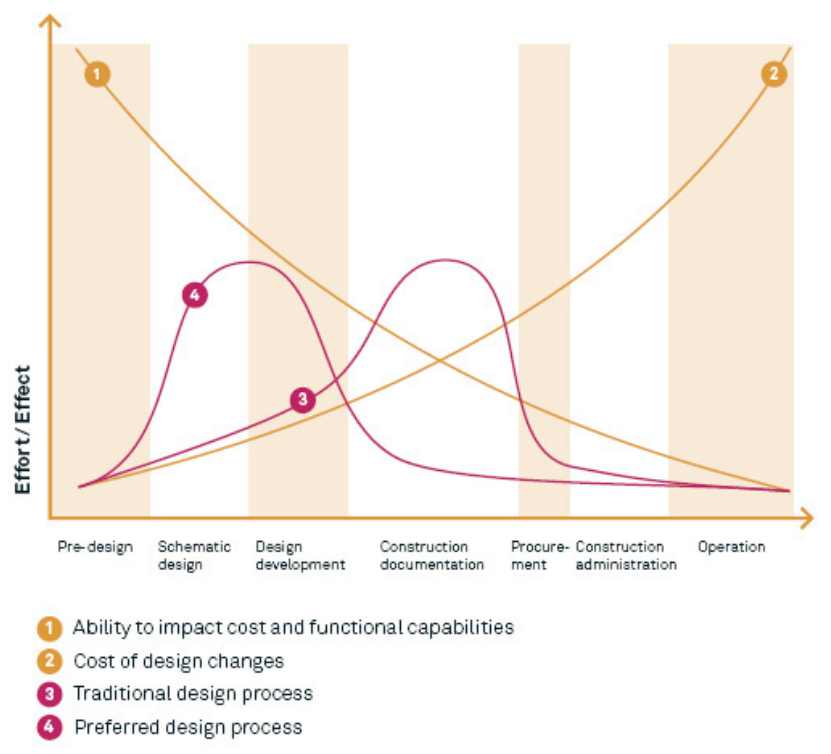

Figure 2. Productivity \& BIM (Fallon and Hagen, 2006)

\section{PILOT STUDIO}

Within a pilot studio setting, this paper investigates the optimal combination of current design modeling methods in order to allow the adoption of BIM at the early stage of design process. The School of Architecture at the University of Hawai'i at Manoa offered a pilot design studio based upon BIM. Its design project was to prepare a design proposal for a new residential high-rise condominium complex of approximately 230,000 square feet in the city of Honolulu.

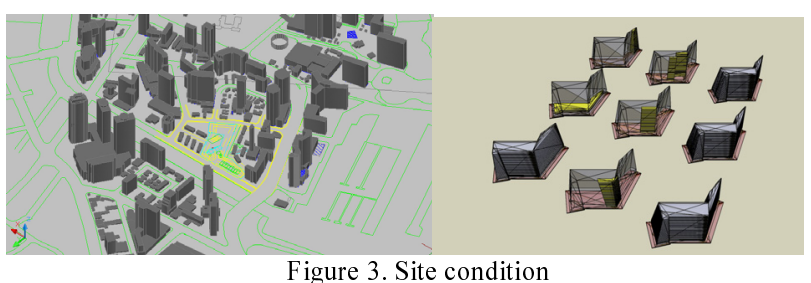

A basic unit of the studio consisted of five students, four professional mentors (construction management, structure\& system, professional practice, and design technology), a client and a project manager. During the studio, students employed three ways of design modeling methods including manual modeling (MM), geometric modeling (GM) and BIM through different phases of the design process. MM includes freehand sketches and physical modeling. SketchUp, FormZ, and AutoCAD are employed for GM. Students applied Autodesk Revit or ArchiCAD for BIM.

For the first four weeks, there was the intensive training of BIM applications (Autodesk Revit or ArchiCAD) for the students. This training session included the one-week introduction of four professional areas including construction management, structure\& system, professional practice, and design technology. The rest of time schedule for this studio are three weeks for concept design, six weeks for schematic design \& partial design development, two weeks for document preparation, one week for midterm presentation, and one week for final presentation.

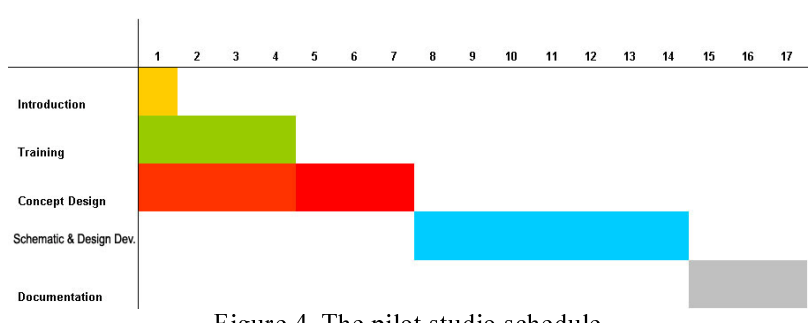

Figure 4. The pilot studio schedule

This studio also had three ways of design communication. The first was the weekly-based "one to one" communication between a student and a mentor. The second was the monthly-based communication between a student and the four mentors, which is "one to multiple" communication. The third was an irregular time-based communication requested by a student or a mentor. It is important to note that the design communication introduced in the studio was a traditional pin-ups or desk critic. The content of the design communication was a sharing of the building information of each student's design progress with the rest of the basic unit members. The presentation of the communication was based upon the parametric models of the student's project and other meta-data attached to the model in digital format.

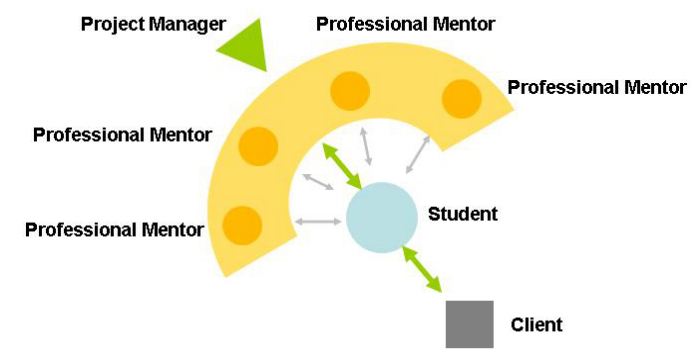

Figure 5. Design communication

This design communication was essential for the success of the design project because each student develops his/her design project based upon the communication with the rest of the basic unit members. Nevertheless, it was 
quite challenging to each student, since s/he had to establish the best interface(s) for this design communication with four different specialists, the client, and the project manager. It led the student to explore and enhance his/her own BIM procedure and selection of preliminary design computer applications for the migration of BIM into his/her architectural design process. Each student's evolutionary adaptation of the digital technologies that maximizes the use of BIM in the design process was the core of this pilot design studio. The data size of BIM of each student's design project increased as the design communication grew.

\section{STUDIO OUTCOMES}

During this studio, the students made conceptual design, schematic design, and partial design development of a given project. Upon the completion of the project, the student made the final presentation of each project and submitted the design process description of the project. The student's design work and her/his presentation were evaluated according to the degree of satisfying the need of a client with the consideration of four different areas, which are construction management, structure \& system, professional practice, and design technology. The design process description from each student became an instrumental yardstick to measure the degree of her/his utilizing BIM in a design project with various design applications. It showed the efficiency and effectiveness of the student's usage of design applications for making the fluent transition of their design idea to BIM. The design process description was composed of 1) the strategy for selecting various design modeling methods, 2) the time record of applying them for each procedure, and 3) the problems and the reflections on their design methods and usage of the design tools.

\section{STRATEGIES FOR DESIGN MODELING METHODS}

Students explored various design modeling methods and applications for MM -freehand sketches \& physical modeling, GM, and BIM. It is important to note that they explored each application as a design method not as a mere tool. It means that they investigated an optimized combination and sequence of using the applications for increasing both productivity and creativity in their design processes. Each student developed different strategies according to 1) the efficiency and effectiveness of design communication, 2) his/her skills of the design applications, and 3 ) the level of understanding the building information.

\section{(1) BIM as a Design Tool}

The early adoption of BIM in the design process provides essential design resources for establishing a convenient design communication between mentors and students. All the necessary design components are able to be propagated from the outcomes of BIM based upon the design communication. Most students using this strategy already have some strength in various GM applications. This al- lows them to explore various GM applications for optimal data exchange with BIM process.

From the beginning of the design process, Autodesk Revit or ArchiCAD are employed for defining a threedimensional design boundary according to given site conditions such as circulation, shape, floor area ratio (FAR) and maximum building height regulation. Within the boundary, various design concepts are tested with freehand sketches, a kind of MM, and GM is performed with SketchUp. During the GM process, with its high degree of design flexibility in GM, SketchUp is employed for developing various spatial containers, which are ready to be filled with architectural components already built in Autodesk Revit.

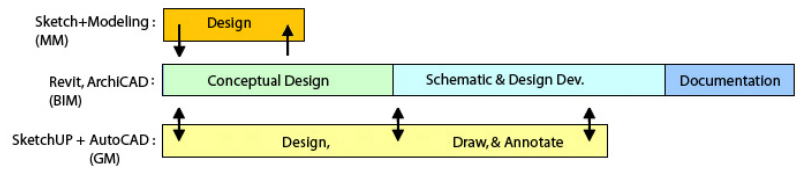

Figure 6. A diagram of BIM as a design tool

With SketchUp, students transform the given threedimensional mass model according to their concepts and divide it into the group of small objects that satisfy functional, structural, and environmental requirements. Various forms developed in SketchUp need to be designed for accepting meta-data stored in the database of Autodesk Revit.
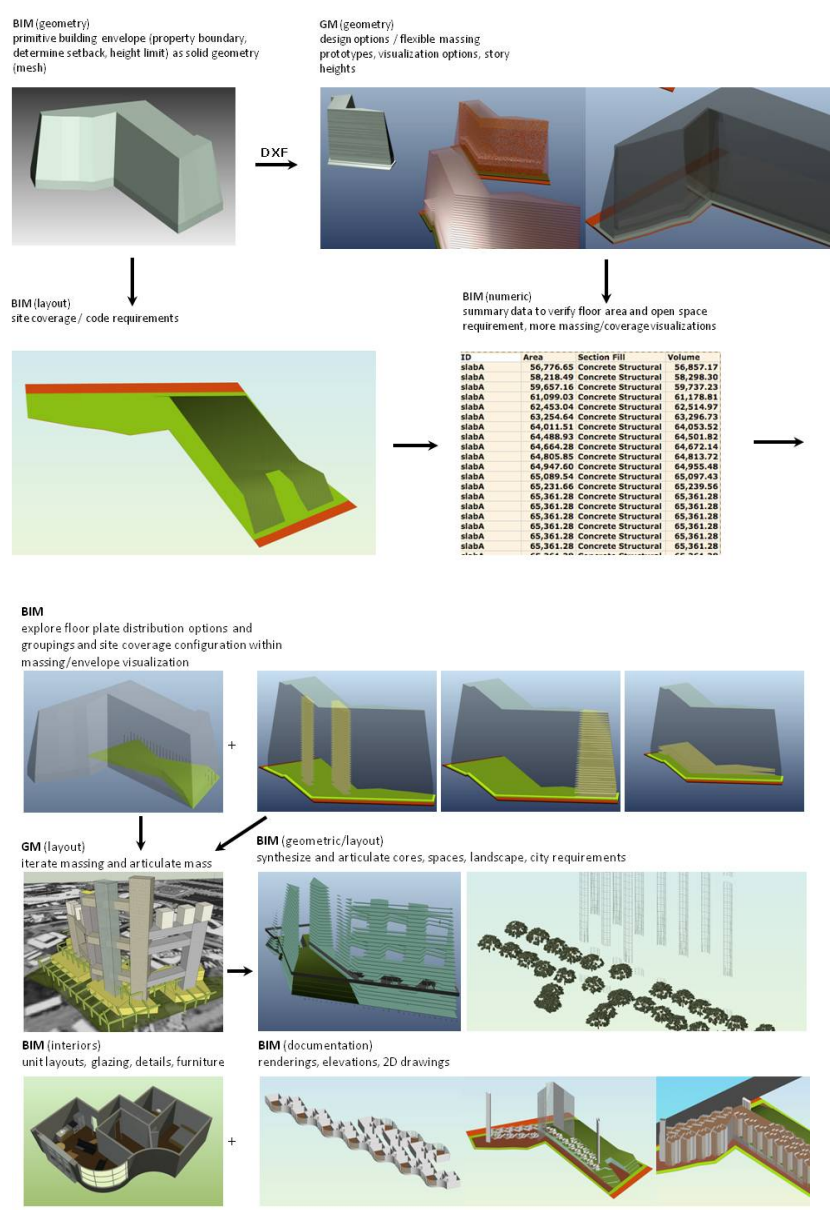

Figure 7. Student designs with BIM as a design tool 
Therefore, in this strategy, the usage of SketchUp is not limited to be a geometric modeler for establishing numeric data to create a geometric form, but a pre-building information modeler to accommodate advanced information regarding building realization. The process of making the spatial containers is instrumental for enhancing the interoperability between GM and BIM, and for resolving the issues of the limited morphological complexity within current BIM applications.

Students using this strategy spent average 134 hours for this project, about 29 hours less than the other strategy. The students used BIM for more than $70 \%$ of the total amount of time. Of this, average $33.3 \%$ of BIM usage occurred in the conceptual design, $37.7 \%$ of BIM usage in the schematic design, and, $29 \%$ of BIM usage in the documentation process.

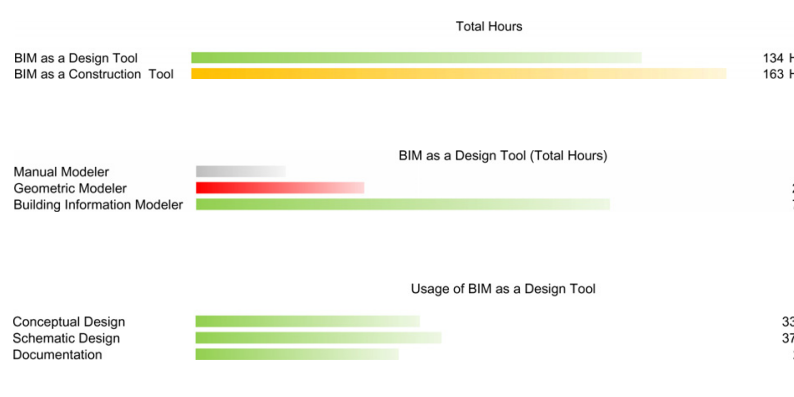

Figure 8. Usage of BIM as a design tool

(2) BIM as a Construction Tool

Most current architectural firms employ this design strategy for adopting BIM with design applications already built in their firms. With the freehand sketches, a kind of MM, a design concept is developed under given site conditions. The two-dimensional drawings and threedimensional mass models are developed in AutoCAD (GM). The developed three-dimensional mass models are reconstructed within Autodesk Revit (BIM) for assigning detailed architectural information. The final design is developed through continuous design exchanges between GM and BIM.

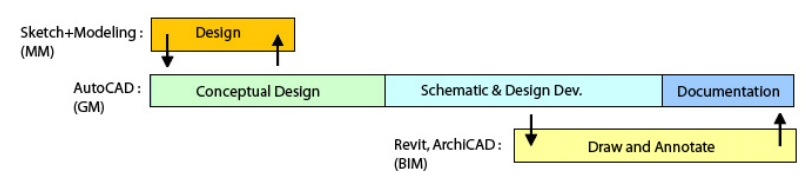

Figure 9. A diagram of BIM as a construction tool

The easiness of manipulating freehand sketch, and AutoCAD provides the strength and efficiency of this strategy until the transition from GM with AutoCAD to BIM with Autodesk Revit. However, with this strategy, after geometric models are generated for representing a design concept with AutoCAD, another modeling process needs to be made in Autodesk Revit. It means that BIM within Autodesk Revit needs to be developed as an additional process. It is because the conversion of the imported mass models to the components in Autodesk Revit is not fully accomplished yet due to the lack of meta-data defining process. In order to make a smooth conversion between these applications, the geometric models within AutoCAD should be layered and partitioned properly in order to accept architectural information in the advanced database system of Autodesk Revit. This strategy requires almost twice amount of time load and efforts compared to other design strategy. Also, the clumsiness of current BIM applications still draws the limitation of BIM in the creativity, especially in making various descriptive geometric models.

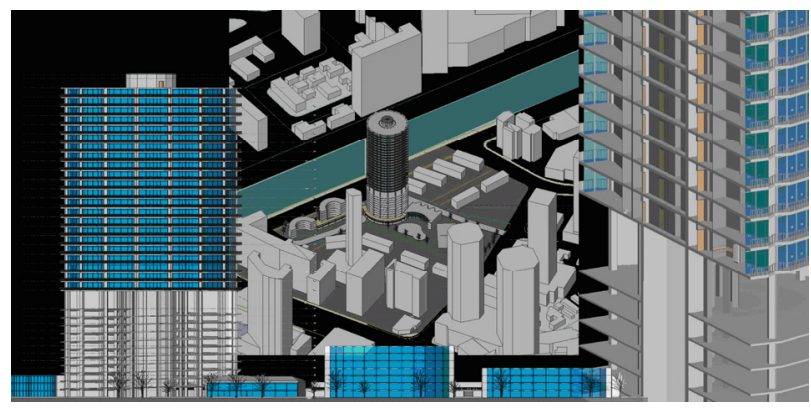

Figure 10. Student designs with BIM as a construction tool

Most students using this strategy are very comfortable with AutoCAD 2D \& 3D modeling process. Before using BIM applications, students construct a complete GM of the project. Their inclination to use AutoCAD delays the use of BIM applications. In addition, only with the geometric models, it is difficult to expect the design communication with mentors from four different professional areas such as construction management, structure \& system, professional practice, and design technology. BIM is employed as a mere tool for constructing another set of geometric models and preparing detailed construction documentations.

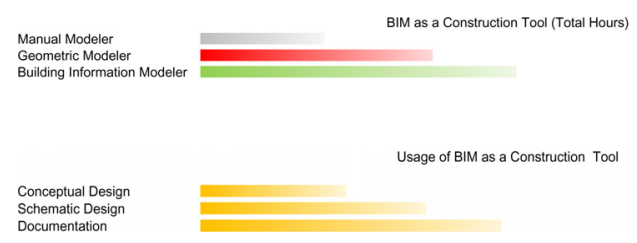

Figure 11. Usage of BIM as a construction tool

Students using this strategy spent average 163 hours for this project. $60 \%$ of studio students employed BIM as a construction tool. They employed BIM for average 52\% of the total amount of time, of which. Average $49 \%$ of BIM usage was concentrated in the documentation stage. Dur- 
ing the schematic design phase, $34 \%$ of BIM usage was made. For the conceptual design phase, just $17 \%$ of the BIM usage was applied.

\section{(3) Existing Problems}

The steep learning curve for current BIM applications and the built-in limitations of the BIM applications still presented a number of obstacles resulting in a rough schematic design with the need for further additional development. For a month, the intensive training of BIM applications for the students was made and some of the students in the studio already had the basic skills of the applications. However, when a BIM application was introduced as a method in the combination with other GM applications, the students had to deal with totally different design environments with which they were not familiar. Therefore, the problem was how to exchange their design outcomes from various applications along with the BIM application, rather than how to use the BIM application alone in the design process.

Current BIM applications require relatively high level of understanding architectural components. The applications require students to make the definition of various architectural details from the process of exploring various geometric forms. It is not generic to architectural design process, which is based upon a form-making that most designers are familiar with. It becomes a huge burden to the students who are not familiar with the detailed architectural information such as what kind of wall, how high, how thick, how wide, with what materials, and on what level etc. It is overwhelming for the students to decide the detailed architectural information from the beginning of the design process.

In addition, when geometric models were received by Autodesk Revit, a BIM application, the models generated as a basic spatial container or placeholder in GM applications such as SketchUp or AutoCAD, basically need to be reconfigured with a set of information. The spatial container represents a geometric model imported from the GM applications for attaching meta-data including detailed architectural information in BIM application. For example, Autodesk Revit stores and treats various walls imported from SketchUp as the same family members while there might be a number of differences of the walls within the family. This requires the reconfigurations of the different types of wall in Autodesk Revit. Current management system of Autodesk Revit does not make convenient information exchanges from the outcome of GM to various architectural components within Autodesk Revit.

\section{DISCUSSION}

During this studio, the students made conceptual design, schematic design, partial design development, and documentation of a new residential high-rise condominium complex, which has approximately 230,000 square feet, within the 16 weeks of time span. $40 \%$ of the students employed BIM as a design tool and $60 \%$ of the students BIM as a construction tool. Students considering BIM as a construction tool had a high level of manipulating skills with a single GM application, AutoCAD. The comfort zone that the students have in AutoCAD limits their design exploration within AutoCAD until the end of partial design development phase. According to the familiarity of this specific GM application and its easy data transfer to BIM application, the total amount of time to finish the project with BIM as a construction tool was supposed to be shorter than with the one as a design tool. However, BIM as a construction tool took 163 hours, which are 29 hours more than the total amount of time with BIM as a design tool. Additional $18 \%$ of the total hours are consumed with BIM as a construction tool. Also, the students considering BIM as a construction tool preferred to find simplified geometric solutions for their design problems. The lack of BIM usage at early design phase created the difficulty of managing various design information attached to geometric object with performing the update and sharing of the information among different disciplinary areas until the end of partial design development phase. Also, it did not allow the ability for modifying digital design data with innovative parametrically building modeling technology. Basically it caused the difficulty of 1 ) establishing a design communication with mentors from four different professional areas such as construction management, structure \& system, professional practice, and design technology and 2) modifying their design projects the feedbacks from the mentors. The weak design communication from the lack of BIM usage became a hindrance for increasing design project productivity and flexibility in building design process. It required the additional amount of time and efforts for solving various design problems. It caused a low quality of design solution and the decrease of design productivity.

Students considering BIM as a design tool were already able to manipulate various GM applications and had previous experience of data exchange among different applications. They understood the advantage of data exchange in design process in order to increase the interoperability and versatility of design data. BIM as a design tool strategy employed BIM applications for $72 \%$ of the total amount of time. Its usage was well distributed into different design phases such as 33\% in conceptual design phase, 38\% in schematic phase, and $29 \%$ in documentation phase. With this balanced usage of BIM in design process, students with BIM as a design tool had an advantage for establishing a better design communication with the mentors. Also, with the power of data exchange between GM and BIM applications, they had a relatively high degree of freedom in form-making. BIM as a design tool strategy was superior to the other strategy in both productivity and creativity through various design phases. It proves that the early adoption of BIM increases not only productivity but also creativity in building design process.

In order to enhance the employment of BIM as a design tool in building design process, the following issues still need to be considered. Current BIM application alone provides a low degree of design freedom. Moreover, they are 
difficult to learn. In addition, due to the short history of the BIM applications, the interoperability with other existing applications is not fully achieved. However, the outcomes from this studio show that GM applications such as SketchUp, FormZ, or AutoCAD can be utilized for making various spatial containers or placeholders, in order to afford the detailed information of architectural components when the models are transferred to BIM applications. With this object-oriented concept of placeholder making, a designer is able to maximize the flexibility in descriptive geometry using GM applications with minimizing the additional efforts for information modeling from GM to BIM. It shows the use of GM and BIM applications as a design method not as a mere drafting tool or GM tool. In addition, "Massing" tool built in the BIM applications shows another possibility to make a connection between BIM and GM from BIM side. "Massing" tool is a built-in conceptual modeling function of BIM application that allows a designer to create various geometric models. It allows a designer to perform basic geometric explorations and an object-oriented thinking with make various spatial containers or placeholders within BIM. The enhancement of "Massing" tool in BIM will increase the portion of GM within BIM and ease the learning curve of BIM applications. It will invite more designers to employ BIM at the early stage of design process.

\section{REFERENCES}

Abelson, H. and Sussman, G. J. (1996) Structure and Interpretation of Programs, The MIT press, Cambridge, Massachusetts, 79-93.

Bernstein, P.G. and Pittman, J.H. (2004) "Barriers to the Adoption of Building Information Modeling in the Building Industry," Autodesk White Paper.

Cheng, R. (2006) "Suggestions for an integrative education," AIA Report on integrated practice.

Fallon, K.K. and Hagen, S.R. (2006) "Information for the facility life cycle," AIA Report on integrated practice.

Friedman, D.S. (2006) "Architectural Education on the Verge," AIA APPLIED LEARNING.

Kolarevic, B. (2003) Architecture in the Digital Age: Design and Manufacturing, New York; Spon Press.

Onuma, K.G. (2006) "The twenty first century practitioner," AIA Report on integrated practice.

Mitchell, W.J., Inouye, A.S., and Blumenthal, M.S. (2003) Beyond Productivity: Information Technology, Innovation, and Creativity, Washington D.C.; The National Academic Press.

Ramakrishnan, R. (1998) Database Management Systems, WCB/McGraw-Hill, INC. Boston, Massachusetts, 614645.

Soutou, C. (2000) "Modeling relationships in objectrelational database", Data \& Knowledge Engineering, vol. 36, 79-107.

(Date of Submission : 2010.4.5) 